\title{
Non-puerperal Inversion of the Uterus Caused by Prolapsed Leiomyoma
}

\author{
Sagar Koirala, Ashma Rana, Geeta Gurung, \\ Josie Baral, Sita Pokharel, Smith Giri \\ Dept. Obs/Gyn, TUTH, IOM
}

\begin{abstract}
Non puerperal uterine inversion is rare. Therefore we present such a case in a 78 years old multiparous woman who was evaluated as a case of grossly infected prolapsed leiomyoma $(12 \times 8 \mathrm{~cm})$ that protruded out of vaginal introitus amidst purulent/blood mixed vaginal discharge and the loss of uterine fundus or the uterus from its premises at surgery being indicative of the condition, the uterus being dragged down below by the low corporeal submucosal leiomyoma causing chronic uterine inversion. Total abdominal hysterectomy with bilateral salphingoopherecomy was done thereby pushing the uterus from below.
\end{abstract}

Key words: Non puerperal, uterine inversion, prolapse, leiomyoma

\section{Introduction}

Uterine inversion is a rare complication of the postpartum period; it is even rarer during non-puerperal period and is usually associated with pedunculated submucosal leiomyoma.Only 150 cases has been reported from 1887 to $2006^{1}$. Here we present a case of low corporal leiomyoma with uterine inversion.

\section{Case}

78 years, menopausal, multiparous lady presented with something coming out per vaginum (Fig 1)for four month and heavy per vaginal bleeding for one day. This was accompanied by lower back pain radiating to lower abdomen. There was no associated urinary or bowel symptoms. There was no history of chronic cough or constipation. The birth spacing between each child was 2 to 3 years. She had history of heavy bleeding 26 years back for which she received blood transfusion but she couldn't produce any record for this information.

On examination her general condition was sick looking and pale. Her blood pressure was 100/70 millimiters of mercury. Respiratory, cardiac and abdominal examination revealed no abnormalities. On per vaginal examination $8 \times 6 \mathrm{~cm}$ polypoid growth protruding out of introitus was appreciated with ulceration and reddish discharge. There was no active bleeding.

With the provisional diagnosis of leiomyomatous polyp routine investigation was sent which revealed no abnormalities except hemoglobin level which was

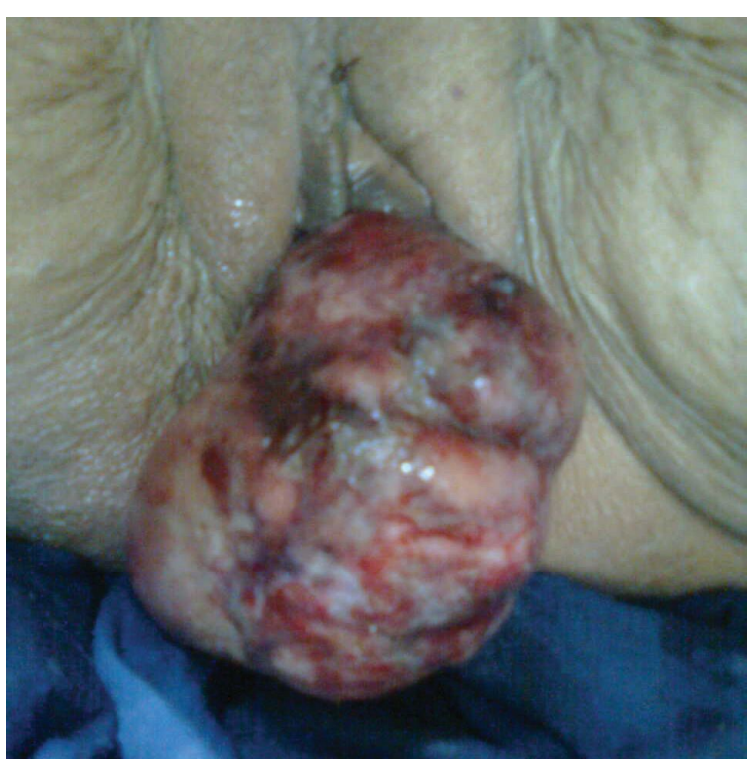

Fig 1. Infected prolapsed myoma

\section{Correspondence}

Sagar Koirala, MBBS

Dept. Obs/Gyn, TUTH, IOM

Mobile : 9841278336

E-mail :sagarkoirala85@gmail.com 


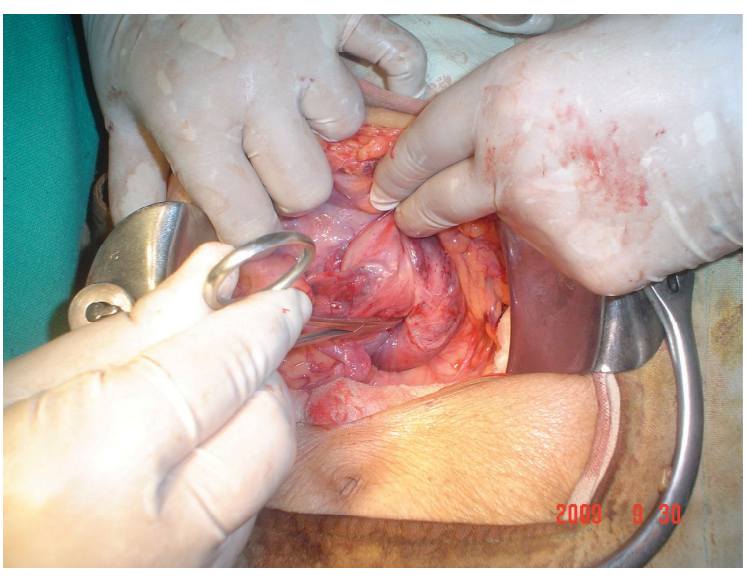

Fig 2. Laparotomy confirming complete disappearance of uterus and adnexa

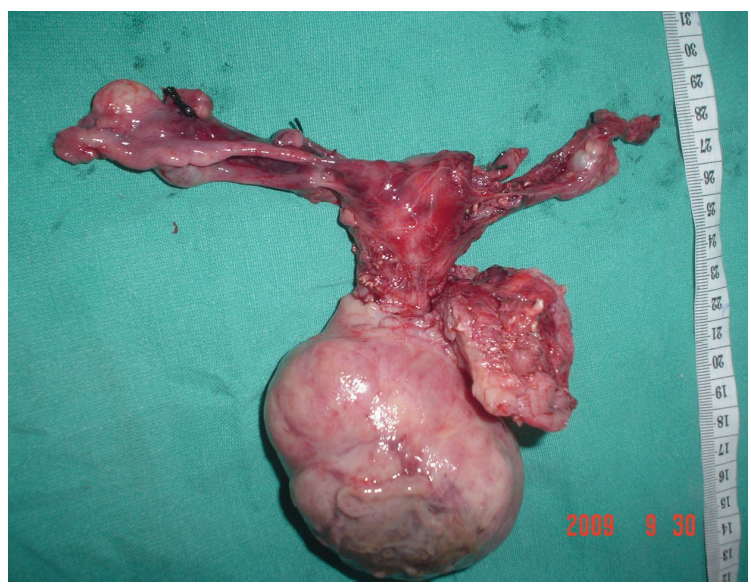

Fig 3. Specimen showing the myoma

$9.1 \mathrm{gm} \%$. She then underwent ultrasonogram which reported as non-visualization of uterus.

She then underwent evaluation under anesthesia during which the size of the mass was found out to be $12 \times 8$ $\mathrm{cm}$ which was protruding from introitus. The cervix couldn't be identified. The possibility of delivery of uterus via vaginal route was doubtful, so planned for abdominal route.

At laparotomy uterus was invisible, represented by dimple (Fig 2)as atrophic uterus (4cm), bilaterally tubes and ovaries were dragged outside the vagina by $12 \times$ $8 \mathrm{~cm}$ sized mass arising from posterior surface of uterus. The patient underwent total abdominal hysterectomy with bilateral salphingoopherctomy. The specimen (Fig 3)was sent for histopathology. The final diagnosis flow corporeal leiomyoma primarily responsible for causing with incomplete inversion of uterus was confirmed.

\section{Comment}

Two types of uterine inversion are known: puerperal and non-puerperal. Uterine inversion is a rare complication of puerperium and non-puerperal inversion is extremely rare ${ }^{1}$.Etiology is not clearly defined; possibilities are thin uterine wall, rapid growth of tumor, fundic localization of tumor, pedunculated tumor, dilatation of cervix by distention of uterine cavity and sudden expulsion of tumor ${ }^{2}$.Menopause is also associated with uterine thinning and hence may lead to uterine inversion. Diagnosis is usually difficult clinically. The determining findings are impalpable fundus of uterus and invisible cervix ${ }^{3}$. The USG reveals indentation of fundic area and a depressed longitudinal groove extending from uterus to the centre of the inverted portion ${ }^{4}$. MRI is the most sensitive diagnostic tool.

\section{Conclusion}

Something coming out per vagina is not always uterovaginal prolapse. Though rare, low corporeal leiomyoma may present as mass protruding out from vagina in postmenopausal ladies. Uterine inversion may be associated not only with pedunculated fundic leiomyoma, but also with low corporeal leiomyoma.

\section{References}

1. Gomez-Lobo V, Burch W, Khanna PC. Nonpuerperal uterine inversion associated with an immature teratoma of the uterus in an adolescent. Obstet Gynecol 2007; 110:491-493

2. Ueda K, Okamoto A, Yamada K, Saito M, Takakura S, Tanaka T, Ochiai K. Non- puerperal inversion of the uterus associated with endometrial cancer: a case report.Int J Clin Oncol 2006; 11(2):153155

3. Schulman JM, Stanton JS. Acute nonpuerperal uterine inversion. South Med J 1981; 74: 11421145

4. Chou HH, Chen CJ, Chu KK. Ultrasonography diagnosis in subacute uterine inversion - a case report. Changgeng Yi Xue Za Zhi 1995; 18: 73-76. 